\section{Vigilância de Fatores de Risco para Doenças Crônicas por Inquérito Telefônico nas capitais dos 26 estados brasileiros e no Distrito Federal (2006)}

\section{Surveillance of risk-factors for chronic diseases through telephone interviews in 27 Brazilian cities (2006)}

Erly Catarina Moura ${ }^{1,2}$

Otaliba Libânio de Morais Neto ${ }^{3}$

Deborah Carvalho Malta ${ }^{3}$

Lenildo de Moura ${ }^{3}$

Nilza Nunes da Silva ${ }^{1,4}$

Regina Bernal'

Rafael Moreira Claro ${ }^{1}$

\section{Carlos Augusto Monteiro ${ }^{1,5}$}

${ }^{1}$ Núcleo de Pesquisas Epidemiológicas em Nutrição e Saúde da Universidade de São Paulo - NUPENS/USP.

${ }^{2}$ Universidade Federal do Pará.

${ }^{3}$ Secretaria de Vigilância em Saúde do Ministério da Saúde

${ }^{4}$ Departamento de Epidemiologia da Faculdade de Saúde Pública da Universidade de São Paulo.

${ }^{5}$ Departamento de Nutrição da Faculdade de Saúde Pública da Universidade de São Paulo.

Correspondência: Dr. Carlos Augusto Monteiro, Departamento de Nutrição - FSP/USP, Av. Dr. Arnaldo, 715, São Paulo, SP CEP 01246-904 E-mail: carlosam@usp.br

\section{Resumo}

Objetivo: Descrever métodos e resultados iniciais do Sistema de Vigilância de Fatores de Risco e Proteção para Doenças Crônicas não Transmissíveis por Inquérito Telefônico - VIGITEL implantado no Brasil em 2006. Métodos: O VIGITEL estudou amostras probabilísticas da população com 18 ou mais anos de idade residente em domicílios conectados à rede de telefonia fixa de cada uma das capitais dos 26 Estados brasileiros e do Distrito Federal (54.369 indivíduos no total, sendo pelo menos 2.000 por cidade). A amostragem foi realizada a partir de cadastros eletrônicos completos das linhas residenciais fixas de cada cidade, envolvendo sorteio de linhas (domicílios) e sorteio de um morador por linha para ser entrevistado. O questionário aplicado investigou características demográficas e socioeconômicas, padrão de alimentação e de atividade física, consumo de cigarros e de bebidas alcoólicas, e peso e altura recordados, entre outros quesitos. Estimativas sobre a freqüência de fatores de risco selecionados, estratificadas por sexo e acompanhadas de Intervalo de Confiança de $95 \%$, foram calculadas para a população adulta de cada cidade empregando-se fatores de ponderação que igualam a composição sociodemográfica da amostra em cada cidade àquela observada no Censo Demográfico de 2000. Estimativas para o conjunto das cidades empregam fator de ponderação adicional que leva em conta a população de adultos de cada cidade. Resultados: Os cinco fatores de risco selecionados (tabagismo, consumo abusivo de bebidas alcoólicas, excesso de peso, consumo de carnes com excesso de gordura e sedentarismo) tenderam a ser mais freqüentes em homens do que em mulheres. Dentre os fatores de proteção, o consumo regular de frutas e hortaliças foi mais freqüente em mulheres do que em homens, observando-se situação inversa no caso da atividade física de lazer. Diferenças substanciais na freqüência dos fatores de risco e proteção foram observa- 
das entre as cidades, com padrões de distribuição regional diferenciados por fator. Discussão: O desempenho do sistema, avaliado a partir da qualidade dos cadastros telefônicos e de taxas de resposta e de recusas, mostrou-se adequado e, de modo geral, superior ao encontrado em sistemas equivalentes existentes em países desenvolvidos. O custo do sistema de $\mathrm{R} \$ 31,15$ por entrevista realizada, foi a metade do custo observado no sistema americano de vigilância de fatores de risco para doenças crônicas por inquérito telefônico e um quinto do custo estimado em inquérito domiciliar tradicional realizado recentemente no Brasil.

Palavras-chave: Doenças crônicas não transmissíveis. Adultos. Entrevistas telefônicas. Consumo alimentar. Atividade física. Tabagismo. Obesidade. Nível socioeconômico. Cidades. Brasil.

\section{Abstract}

Objectives: To describe methods and initial findings of the Surveillance System of Risk and Protective Factors for Chronic Non-Communicable Diseases through Telephone Interviews - VIGITEL implemented in Brazil in 2006. Methods: VIGITEL studied random samples of individuals with 18 years of age or more living in households with telephones in each capital of the 26 Brazilian states and the Federal District (54,369 total individuals, and at least 2,000 per city). Sampling was based on complete electronic telephone directories in each city and included random selection of phone lines (households) and random selection of the household member to be interviewed. The questionnaire investigated demographic and socioeconomic characteristics, diet patterns, physical activity, smoking, consumption of alcoholic beverages, recalled weight and height, and other topics. Prevalence estimates of selected protective and risk factors, stratified by gender with corresponding 95\% Confidence Intervals, were calculated for the adult population of each city using sample weighing factors designed to equalize the sample socio-demographic distribution in each city to the distribution observed in the same city in the Demographic Census of 2000. Estimates were also calculated for all cities together using additional sample weighing that took into account the adult population size of each city. Findings: The five selected risk factors (smoking, excessive consumption of alcoholic beverages, overweight, habit of eating fatty meats, and physical inactivity) were more frequent among men than women. Among protective factors, the regular consumption of fruits and vegetables was more common among women than men and the opposite was seen for leisure-time physical activity. Strong differences among the cities were found for all protective and risk factors, with distinct patterns of regional distribution seen for different factors. Discussion: The performance of the system, evaluated based on the quality of telephone directories and response and refusal rates, was appropriate and in general higher than the performance seen in similar systems of developed countries. The cost of R $\$ 31.15$ per complete interview was half the cost of the Behavioral Risk-Factor Surveillance System and one fifth of the cost estimated for a household survey on risk factors for chronic diseases recently conducted in Brazil.

Keywords: Non-communicable diseases. Adults. Telephone interviews. Food consumption. Physical activity. Smoking. Obesity. Socioeconomic status. Urban population. Brazil. 


\section{Introdução}

As Doenças Crônicas não Transmissíveis (DCNTs) exercem papel muito importante no perfil atual de saúde das populações humanas. Estimativas da Organização Mundial de Saúde (OMS) apontam que as DCNTs já são responsáveis por $58,5 \%$ de todas as mortes ocorridas no mundo e por $45,9 \%$ da carga global de doença ${ }^{1}$. No Brasil, as DCNTs respondem por $62,8 \%$ do total das mortes por causa conhecida ${ }^{2}$. Séries históricas de estatísticas de mortalidade disponíveis para as capitais dos Estados brasileiros indicam que a proporção de mortes por DCNTs aumentou em mais de três vezes entre as décadas de 30 e $90^{3}$.

Estimativas globais da OMS indicam, ainda, que um pequeno conjunto de fatores de risco responde pela grande maioria das mortes por DCNTs e por fração substancial da carga de doenças devida a essas enfermidades. Dentre esses fatores, destacam-se o tabagismo, o consumo abusivo de bebidas alcoólicas, a obesidade, o consumo excessivo de gorduras saturadas (que dão origem às dislipidemias), a ingestão insuficiente de frutas e hortaliças, e a inatividade física ${ }^{1}$.

Como parte do processo de dotar o país de instrumentos eficazes para monitorar a freqüência e distribuição dos principais fatores determinantes das DCNTs, o Ministério da Saúde implantou, no ano de 2006, o sistema VIGITEL - Vigilância de Fatores de Risco e Proteção para Doenças Crônicas por Inquérito Telefônico. Este sistema objetiva o monitoramento contínuo da freqüência e distribuição de fatores de risco e proteção para doenças crônicas em todas as capitais dos 26 Estados brasileiros e no Distrito Federal, apoiando-se para tanto na realização contínua de entrevistas telefônicas assistidas por computador em amostras probabilísticas da população adulta residente em domicílios servidos por linhas fixas de telefone de cada cidade. Este sistema foi previamente testado, com sucesso, na cidade de São $\mathrm{Paulo}^{4} \mathrm{e}$, posteriormente, em Belém, Florianópolis, Goiânia e Salvador pelo Núcleo de Pesquisas Epidemiológicas em Nutrição e Saúde da Universidade de São Paulo - NUPENS/ USP.

Neste artigo são apresentados resultados iniciais relativos ao primeiro ano de operação do sistema VIGITEL. Esses resultados dotam o Distrito Federal e todas as capitais dos 26 Estados brasileiros - onde, segundo o Censo Demográfico de 2000, vivem $25,2 \%$ de todos os adultos do país de informações atualizadas sobre a freqüência de importantes determinantes de doenças crônicas em nosso meio, ao mesmo tempo em que geram uma linha de base para o monitoramento futuro desses fatores.

\section{Material e Métodos}

\section{Amostragem}

Os procedimentos de amostragem empregados pelo sistema VIGITEL visam obter, em cada uma das capitais dos 26 Estados brasileiros e no Distrito Federal, amostras probabilísticas da população de adultos residentes em domicílios servidos por pelo menos uma linha telefônica fixa no ano. O sistema estabelece um tamanho amostral mínimo de 2.000 indivíduos com 18 ou mais anos de idade em cada cidade, para que se possa estimar com coeficiente de confiança de 95\% e erro máximo de cerca de dois pontos percentuais a freqüência de qualquer fator de risco na população adulta ${ }^{5}$.

A primeira etapa da amostragem do sistema VIGITEL consiste no sorteio sistemático de 5.000 linhas telefônicas por cidade. Este sorteio, estratificado de acordo com a região da cidade ou o prefixo das linhas, é realizado a partir de cadastro eletrônico de linhas residenciais fornecido pelas empresas de serviço telefônico que cobrem as cidades. A seguir, as linhas sorteadas em cada cidade são re-sorteadas e divididas em 25 réplicas de 200 linhas, cada réplica reproduzindo a mesma proporção de li- 
nhas por região da cidade ou prefixo telefônico. A divisão da amostra integral em réplicas é feita, essencialmente, em função da dificuldade em se estimar previamente a proporção das linhas do cadastro que serão elegíveis para o sistema (linhas residenciais ativas) e, portanto, o total de linhas a ser sorteado para se chegar a 2.000 entrevistas. No ano de 2006, a partir dos cadastros telefônicos das três empresas que servem as 27 cidades, foram sorteadas 135.000 linhas telefônicas (5.000 por cidade). Com exceção do Distrito Federal, onde o cadastro fornecido pela empresa telefônica estava limitado a quatro regiões administrativas, nas demais cidades contouse com cadastros completos das linhas residenciais. Como poderá ser visto a seguir, foram utilizadas, em média, vinte réplicas por cidade, variando entre 16 réplicas em Belo Horizonte e 25 réplicas em Porto Alegre.

A segunda etapa da amostragem do VIGITEL foi executada em paralelo à execução das entrevistas, envolvendo inicialmente a identificação, dentre as linhas sorteadas, daquelas que são elegíveis para o sistema, ou seja, linhas residenciais ativas. Não foram elegíveis para o sistema as linhas que correspondem a empresas, que não mais existem ou que se encontram fora de serviço, além das linhas que não respondem a dez chamadas feitas em dias e horários variados, incluindo sábados e domingos e períodos noturnos, e que, provavelmente, correspondem a domicílios fechados. No ano de 2006, no conjunto das 27 cidades, o sistema VIGITEL fez ligações para 107.200 linhas telefônicas distribuídas em 536 réplicas, identificando 76.330 linhas elegíveis.

Para cada linha elegível, uma vez obtida a aquiescência dos seus usuários em participar do sistema, procedeu-se à enumeração dos indivíduos com 18 ou mais anos de idade que residiam no domicílio e, a seguir, ao sorteio de um desses indivíduos para ser entrevistado. No ano de 2006, as ligações feitas para as 76.330 linhas elegíveis redundaram em 54.369 entrevistas completas, o que indica uma taxa de resposta do sistema (entrevistas realizadas/ linhas telefônicas sorteadas elegíveis para entrevista) de $71,1 \%$, variando de $64,4 \%$ em Porto Alegre a 81,0\% em Palmas.

Cerca de dois terços das linhas elegíveis para as quais não houve entrevista corresponderam a situações em que não foi possível o contato telefônico inicial com seus usuários (linhas permanentemente ocupadas, com sinal de fax ou conectadas à secretária eletrônica) ou quando não foi possível encontrar o individuo sorteado no domicílio, mesmo depois de várias tentativas de aprazamento e depois de pelo menos dez ligações feitas em dias e horários variados. A taxa de recusas do sistema (entrevistas recusadas/linhas telefônicas sorteadas elegíveis para entrevista), seja no contato inicial com o domicílio, seja após o sorteio do indivíduo a ser entrevistado, foi de $9,1 \%$, variando de $5,4 \%$ em Palmas a 15\% em Porto Alegre.

O número total de adultos entrevistados pelo VIGITEL em 2006 foi de 54.369, sendo 21.294 homens e 33.075 mulheres. O número de adultos entrevistados por cidade variou entre 2.008 no Distrito Federal e 2.031 em Aracaju. O número de homens entrevistados variou entre $728 \mathrm{em}$ Porto Alegre e 878 em Palmas e o número de mulheres entre 1.185 em Macapá e 1.301 em Aracaju.

\section{Coleta de dados}

As entrevistas telefônicas foram feitas entre agosto e dezembro de 2006 por uma empresa comercial de pesquisa de opinião sediada em Belo Horizonte. A equipe responsável pelas entrevistas, envolvendo 60 entrevistadores, quatro supervisores e um coordenador, recebeu treinamento prévio e foi supervisionada continuamente durante a operação do sistema por um dos autores (ECM).

O questionário do sistema VIGITEL (disponível em: http://hygeia.fsp.usp.br/ nupens/questionario2006.pdf) foi construído de modo a viabilizar a opção do sis- 
tema pela realização de entrevistas telefônicas feitas com o emprego de computadores, ou seja, entrevistas cujas perguntas são lidas diretamente da tela de um monitor de vídeo e cujas respostas são registradas direta e imediatamente em meio eletrônico. Este questionário permite, ainda, o sorteio automático do membro do domicílio que será entrevistado, o salto automático de questões não aplicáveis em face de respostas anteriores, a crítica imediata de respostas não válidas e a cronometragem da duração da entrevista, além de propiciar a alimentação direta e contínua do banco de dados do sistema.

As perguntas do questionário VIGITEL, curtas e simples, abordam:

- características demográficas e socioeconômicas dos indivíduos (idade, sexo, estado civil, etnicidade, nível de escolaridade, número de pessoas e cômodos no domicílio, número de adultos e número de linhas telefônicas);

- características do padrão de alimentação e de atividade física associadas à ocorrência de DCNTs (por exemplo: freqüência do consumo de frutas e hortaliças e de alimentos fonte de gordura saturada e freqüência e duração da prática de exercícios físicos e do hábito de assistir televisão);

- peso e altura recordados;

- freqüência do consumo de cigarros e de bebidas alcoólicas; e

- auto-avaliação do estado de saúde do entrevistado e referência a diagnóstico médico anterior de hipertensão arterial, diabetes e colesterol elevado.

O processo de construção do questionário do sistema levou em conta vários modelos de questionários simplificados utilizados por sistemas de monitoramento de fatores de risco para doenças crônicas ${ }^{6,7}$ e a experiência acumulada nos testes de implantação do sistema na cidade de São Paulo $^{4}$ e em outras quatro capitais de Estados brasileiros. No ano de 2006, a duração média das entrevistas realizadas pelo sistema VIGITEL foi de 7,4 minutos (mediana 6,9 minutos, desvio padrão $3,3 \mathrm{mi}$ nutos).

\section{Análise de dados}

Neste artigo, são apresentadas estimativas do sistema VIGITEL, estratificadas por gênero, para a freqüência (e correspondente intervalo de confiança de 95\%) de fatores selecionados de risco e proteção para DCNTs. As estimativas são fornecidas para a população adulta de cada uma das capitais dos 26 Estados brasileiros e do Distrito Federal e, também, para o conjunto da população adulta dessas 27 cidades.

A seleção dos fatores de risco e proteção para doenças crônicas levou em conta sua importância para a determinação da carga total de doença estimada pela OMS para a região das Américas onde se encontra o Brasil ${ }^{1}$. Assim, foram incluídos hábito de fumar (proporção de indivíduos que fumam, independentemente da freqüência e intensidade do hábito de fumar); consumo abusivo de bebidas alcoólicas (proporção de indivíduos que, nos últimos 30 dias, chegaram a consumir, em um único dia, mais de quatro (mulheres) ou cinco (homens) doses de bebida alcoólica); excesso de peso (proporção de indivíduos com Indice de Massa Corporal igual ou superior a $25 \mathrm{~kg} / \mathrm{m}^{2}$ ), hábito de consumir carnes com excesso de gordura (proporção de individuos que costumam consumir carne vermelha gordurosa ou carne de frango com pele sem remoção da gordura visível do alimento); e sedentarismo (proporção de individuos que não praticaram qualquer atividade fisica de lazer nos últimos três meses, que não realizam esforços físicos intensos no trabalho, que não se deslocam para o trabalho caminhando ou de bicicleta e que não são responsáveis pela "limpeza pesada" de suas casas). Dentre os fatores de proteção, foram incluídos prática suficiente de atividade física no lazer (proporção de indivíduos que praticam atividades físicas no lazer de intensidade leve ou moderada por pelo menos 30 
minutos diários em cinco ou mais dias por semana ou atividades de intensidade vigorosa por pelo menos 20 minutos diários em três ou mais dias da semana) e consumo regular de frutas e hortaliças (proporção de indivíduos que consomem frutas e hortaliças em cinco ou mais dias da semana). Considerou-se como dose de bebida alcoólica uma lata de cerveja, uma taça de vinho ou uma dose de bebida destilada. A intensidade da atividade física no lazer foi classificada com base na intensidade estimada para o esporte ou exercício referido pelo entrevistado ${ }^{8}$.

Todas as estimativas apresentadas neste artigo levam em conta fatores de ponderação que são atribuídos a cada indivíduo entrevistado pelo sistema VIGITEL. O peso final de cada entrevistado em cada uma das 27 cidades é o resultado da multiplicação de três fatores. O primeiro desses fatores é o inverso do número de linhas telefônicas no domicílio do entrevistado, o qual corrige a maior chance que indivíduos de domicílios com mais de uma linha telefônica tiveram de ser selecionados para a amostra. O segundo fator é o número de adultos no domicílio do entrevistado, o qual corrige a menor chance que indivíduos de domicílios habitados por mais pessoas tiveram de ser selecionados para a amostra. O terceiro fator, denominado peso pós-estratificação, objetiva igualar a composição sociodemográfica da amostra de adultos estudada pelo VIGITEL em cada cidade à composição sociodemográfica da população adulta total da cidade.

Para a obtenção do peso pós-estratificação, a amostra de indivíduos estudada pelo VIGITEL em cada cidade, já incorporando os dois fatores de ponderação mencionados anteriormente, foi distribuída em 36 categorias sociodemográficas resultantes da estratificação da amostra segundo sexo(masculino e feminino), faixas etárias (18-24, 25-34, 35-44, 45-54, 55-64 e 65 e mais anos de idade) e níveis de escolaridade $(0-8,9-11$ e 12 ou mais anos de escolaridade). A seguir, procedeu- se à mesma distribuição para a amostra de adultos estudada em cada cidade pelo Censo Demográfico de 2000 - amostra correspondente a $10 \%$ do total de domicílios. O peso pós-estratificação, próprio de cada categoria sociodemográfica, é a razão entre a freqüência relativa da categoria na amostra do Censo e a freqüência relativa da mesma categoria na amostra do sistema VIGITEL.

Para se produzir estimativas relativas ao conjunto da população adulta das 27 cidades, o produto dos três pesos anteriores foi multiplicado por um quarto fator de ponderação que levou em conta diferenças no tamanho populacional de cada cidade. Este fator, próprio de cada cidade, era a razão entre a proporção do total de adultos da cidade no total de adultos das 27 cidades, fornecida pelo Censo Demográfico de 2000, e a proporção do total de entrevistas do VIGITEL na cidade no total de entrevistas do VIGITEL nas 27 cidades.

Para o processamento de dados e as análises estatísticas divulgadas neste artigo, utilizou-se o aplicativo "STATA, versão 9", empregando-se comandos que computam proporções com intervalos de confiança que levam em conta o emprego de fatores de ponderação ${ }^{9}$.

\section{Aspectos éticos}

Por se tratar de entrevista por telefone, o consentimento livre e esclarecido foi substituído pelo consentimento verbal obtido por ocasião dos contatos telefônicos com os entrevistados. O projeto de implantação do VIGITEL foi aprovado pelo Comitê Nacional de Ética em Pesquisa para Seres Humanos do Ministério da Saúde.

\section{Resultados}

São apresentadas a seguir as estimativas do sistema VIGITEL, estratificadas por sexo, para a população adulta de cada uma das capitais dos 26 Estados brasileiros e do Distrito Federal e para o conjunto da população adulta dessas cidades. 


\section{Freqüência de fumantes}

A freqüência de fumantes no conjunto da população adulta das 27 cidades estudadas foi de $16,2 \%$, variando entre $9,5 \% \mathrm{em}$ Salvador e 21,2\% em Porto Alegre e Rio Branco. O hábito de fumar se mostra mais disseminado entre homens do que entre mulheres em todas as cidades, com exceção de Goiânia e Rio de Janeiro, onde a freqüência de fumantes é semelhante nos dois sexos. Entre os homens, as freqüên- cias mais altas foram encontradas em cidades das regiões Norte e Sul - Porto Velho (25,0\%), Porto Alegre (26,3\%) e Macapá $(29,4 \%)$ - e as mais baixas no Rio de Janeiro $(16,1 \%)$, Goiânia $(15,9 \%)$ e Salvador $(12,3 \%)$. Entre as mulheres, as maiores freqüências foram também observadas em cidades das regiões Norte e Sul - Curitiba (15,9\%), Porto Alegre $(17,0 \%)$ e Rio Branco $(17,9 \%)$ - e as menores em cidades da região Nordeste - São Luís (8,1\%), Aracaju $(8,1 \%)$ e Salvador $(7,2 \%)$ (Tabela 1$)$.

Tabela 1 - Percentual de adultos (e" 18 anos) fumantes, por sexo, segundo as capitais dos Estados brasileiros e Distrito Federal*. VIGITEL, 2006.

Table 1 - Percentage of adults (e"18 years) who smoke, by gender, according to capitals of Brazilian States and the Federal District *. VIGITEL, 2006.

\begin{tabular}{|c|c|c|c|c|c|c|}
\hline \multirow{3}{*}{ Capitais / DF } & \multirow{2}{*}{\multicolumn{2}{|c|}{ Total }} & \multicolumn{4}{|c|}{ Sexo } \\
\hline & & & \multicolumn{2}{|c|}{ Masculino } & \multicolumn{2}{|c|}{ Feminino } \\
\hline & $\%$ & IC95\% & $\%$ & IC95\% & $\%$ & IC95\% \\
\hline Aracaju & 12,3 & $10,9-13,7$ & 17,5 & $14,7-20,2$ & 8,1 & $6,6-9,6$ \\
\hline Belém & 14,4 & $12,9-15,9$ & 19,5 & $16,7-22,3$ & 10,1 & $8,4-11,7$ \\
\hline Belo Horizonte & 16,2 & $14,6-17,9$ & 21,9 & $19,0-24,8$ & 11,4 & $9,6-13,2$ \\
\hline Boa Vista & 16,8 & $15,2-18,4$ & 23,2 & $20,3-26,1$ & 10,5 & $8,8-12,2$ \\
\hline Campo Grande & 15,0 & $13,4-16,5$ & 20,5 & $17,7-23,4$ & 9,9 & $8,3-11,6$ \\
\hline Cuiabá & 17,1 & $15,4-18,7$ & 23,8 & $20,9-26,7$ & 10,9 & $9,1-12,7$ \\
\hline Curitiba & 18,8 & $17,1-20,5$ & 22,1 & $19,1-25,0$ & 15,9 & $13,8-17,9$ \\
\hline Florianópolis & 18,7 & $17,0-20,4$ & 21,9 & $19,1-24,8$ & 15,8 & $13,7-17,8$ \\
\hline Fortaleza & 16,3 & $14,7-17,9$ & 19,6 & $16,8-22,4$ & 13,6 & $11,7-15,5$ \\
\hline Goiânia & 14,0 & $12,5-15,5$ & 15,9 & $13,31-18,5$ & 12,4 & $10,6-14,2$ \\
\hline João Pessoa & 15,9 & $14,3-17,5$ & 21,1 & $18,2-24,0$ & 11,6 & $9,8-13,4$ \\
\hline Macapá & 19,1 & $17,4-20,9$ & 29,4 & $26,3-32,5$ & 9,5 & $7,8-11,1$ \\
\hline Maceió & 13,9 & $12,4-15,4$ & 17,9 & $15,2-20,6$ & 10,5 & $8,8-12,2$ \\
\hline Manaus & 14,5 & $13,0-16,1$ & 20,7 & $17,9-23,4$ & 8,9 & $7,3-10,5$ \\
\hline Natal & 13,5 & $12,0-15,0$ & 17,5 & $14,8-20,2$ & 10,3 & $8,6-12,0$ \\
\hline Palmas & 13,8 & $12,3-15,3$ & 18,4 & $15,9-21,0$ & 9,1 & $7,4-10,8$ \\
\hline Porto Alegre & 21,2 & $19,4-23,0$ & 26,3 & $23,1-29,5$ & 17,0 & $14,9-19,0$ \\
\hline Porto Velho & 19,2 & $17,5-20,9$ & 25,0 & $22,1-27,9$ & 13,6 & $11,6-15,5$ \\
\hline Recife & 14,7 & $13,1-16,2$ & 19,3 & $16,4-22,1$ & 11,0 & $9,3-12,7$ \\
\hline Rio Branco & 21,2 & $19,4-23,0$ & 24,8 & $21,9-27,8$ & 17,9 & $15,7-20,0$ \\
\hline Rio de Janeiro & 14,5 & $13,0-16,0$ & 16,1 & $13,4-18,7$ & 13,2 & $11,3-15,1$ \\
\hline Salvador & 9,5 & $8,2-10,8$ & 12,3 & $10,0-14,6$ & 7,2 & $5,8-8,7$ \\
\hline São Luís & 12,1 & $10,7-13,6$ & 17,0 & $14,4-19,6$ & 8,1 & $6,6-9,6$ \\
\hline São Paulo & 18,8 & $17,1-20,5$ & 23,6 & $20,6-26,5$ & 14,6 & $12,6-16,6$ \\
\hline Teresina & 18,3 & $16,6-19,9$ & 24,0 & $21,0-27,0$ & 13,5 & $11,6-15,4$ \\
\hline Vitória & 15,9 & $14,3-17,5$ & 18,7 & $16,0-21,5$ & 13,6 & $11,7-15,5$ \\
\hline Distrito Federal & 17,2 & $15,5-18,8$ & 19,9 & $17,1-22,7$ & 14,9 & $12,9-16,8$ \\
\hline Total & 16,2 & $15,9-16,5$ & 20,3 & $19,7-20,8$ & 12,8 & $12,4-13,1$ \\
\hline
\end{tabular}

* Percentual ponderado para ajustar a distribuição sócio-demográfica da amostra VIGITEL em cada cidade à distribuição da população adulta da cidade no Censo Demográfico de 2000 e, no caso do conjunto das cidades, para levar em conta o peso populacional de cada cidade. VIGITEL: Vigilância de Fatores de Risco e Proteção para Doenças Crônicas por Inquérito Telefônico. IC95\%: Intervalo de Confiança de 95\%.

* Weighed percentage for adjusting the socio-demographic distribution of VIGITEL's sample in each city to the distribution of the adult population of the 2000 Demographic Census and for the set of cities, to take into account the population weight of each city. VIGITEL: Vigilância de Fatores de Risco e Proteção para Doenças Crônicas por Inquérito Telefônico.IC95\%:95\% Confidence Interval. 


\section{Consumo abusivo de bebidas alcoólicas}

A freqüência do consumo abusivo de bebidas alcoólicas (consumo em único dia de mais de quatro doses para mulheres, ou mais de cinco doses para homens) foi de $16,1 \%$ para o conjunto da população adulta das 27 cidades, variando entre 12,0\% em São Paulo e 22,1\% em Salvador. Na maioria das cidades, a freqüência do consumo abusivo de bebidas alcoólicas tendeu a ser duas vezes maior em homens do que em mulheres.
No sexo masculino, as maiores freqüências foram observadas em cidades da região Nordeste - Teresina (32,3\%), Recife $(32,9 \%)$ e Salvador $(33,0 \%)$ - e as menores em cidades do Centro-Sul do país (regiões Centro-Oeste, Sudeste e Sul) - Campo Grande $(22,9 \%)$, Curitiba $(20,6 \%)$ e São Paulo (20,0\%). Entre as mulheres, as maiores freqüências foram observadas em Recife (12,1\%), Salvador $(13,0 \%)$ e Belo Horizonte $(13,2 \%)$, e as menores em São Luís (6,0\%), São Paulo (5,1\%) e Curitiba (4,6\%) (Tabela 2).

Tabela 2 - Percentual de adultos (e•18 anos) que, nos últimos 30 dias, consumiram mais do que quatro doses (mulher) ou cinco doses (homem) de bebida alcoólica em um único dia, por sexo, segundo as capitais dos Estados brasileiros e Distrito Federal*. VIGITEL, 2006.

Table 2 - Percentage of adults (e•18 years) who in the past 30 days, had more than four doses (women) or five doses (men) of alcoholic beverages on a single day, by gender, according to capitals of Brazilian States and the Federal District *. VIGITEL, 2006.

\begin{tabular}{|c|c|c|c|c|c|c|}
\hline \multirow{3}{*}{ Capitais / DF } & \multirow{2}{*}{\multicolumn{2}{|c|}{ Total }} & \multicolumn{4}{|c|}{ Sexo } \\
\hline & & & \multicolumn{2}{|c|}{ Masculino } & \multicolumn{2}{|c|}{ Feminino } \\
\hline & $\%$ & IC95\% & $\%$ & IC95\% & $\%$ & IC95\% \\
\hline Aracaju & 19,3 & $17,6-21,0$ & 31,2 & $27,9-34,6$ & 9,5 & $7,9-11,1$ \\
\hline Belém & 16,8 & $15,1-18,4$ & 26,1 & $23,1-29,2$ & 8,7 & $7,2-10,3$ \\
\hline Belo Horizonte & 19,9 & $18,2-21,7$ & 27,8 & $24,7-31,0$ & 13,2 & $11,3-15,1$ \\
\hline Boa Vista & 14,7 & $13,2-16,3$ & 23,4 & $20,5-26,3$ & 6,1 & $4,7-7,4$ \\
\hline Campo Grande & 15,6 & $14,0-17,2$ & 22,9 & $20,0-25,9$ & 8,9 & $7,3-10,5$ \\
\hline Cuiabá & 18,9 & $17,1-20,6$ & 31,8 & $28,6-35,0$ & 7,0 & $5,6-8,5$ \\
\hline Curitiba & 12,1 & $10,7-13,5$ & 20,6 & $17,8-23,5$ & 4,6 & $3,4-5,8$ \\
\hline Florianópolis & 18,1 & $16,4-19,8$ & 30,2 & $27,0-33,3$ & 7,2 & $5,7-8,7$ \\
\hline Fortaleza & 16,4 & $14,7-18,0$ & 26,3 & $23,2-29,3$ & 8,3 & $6,7-9,8$ \\
\hline Goiânia & 15,6 & $14,1-17,2$ & 24,1 & $21,1-27,1$ & 8,3 & $6,8-9,8$ \\
\hline João Pessoa & 16,9 & $15,3-18,5$ & 29,7 & $26,5-32,9$ & 6,4 & $5,1-7,8$ \\
\hline Macapá & 19,6 & $17,8-21,3$ & 32,0 & $28,9-35,2$ & 7,8 & $6,3-9,4$ \\
\hline Maceió & 17,8 & $16,2-19,5$ & 27,8 & $24,6-30,9$ & 9,5 & $7,9-11,2$ \\
\hline Manaus & 18,6 & $16,9-20,4$ & 31,2 & $28,1-34,3$ & 7,1 & $5,6-8,6$ \\
\hline Natal & 17,0 & $15,3-18,6$ & 29,6 & $26,4-32,9$ & 6,5 & $5,1-7,8$ \\
\hline Palmas & 19,5 & $17,8-21,3$ & 28,5 & $25,5-31,4$ & 10,5 & $8,7-12,2$ \\
\hline Porto Alegre & 15,3 & $13,7-16,9$ & 25,2 & $22,0-28,3$ & 7,2 & $5,8-8,6$ \\
\hline Porto Velho & 17,7 & $16,1-19,4$ & 28,0 & $25,0-31,0$ & 7,7 & $6,2-9,3$ \\
\hline Recife & 21,4 & $19,6-23,2$ & 32,9 & $29,5-36,3$ & 12,1 & $10,3-13,9$ \\
\hline Rio Branco & 16,4 & $14,8-18,0$ & 25,6 & $22,6-28,6$ & 8,0 & $6,4-9,5$ \\
\hline Rio de Janeiro & 16,7 & $15,0-18,3$ & 25,2 & $22,1-28,3$ & 9,5 & $7,9-11,1$ \\
\hline Salvador & 22,1 & $20,3-23,9$ & 33,0 & $29,7-36,2$ & 13,0 & $11,1-14,9$ \\
\hline São Luís & 17,3 & $15,7-19,0$ & 31,0 & $27,8-34,3$ & 6,0 & $4,6-7,2$ \\
\hline São Paulo & 12,0 & $10,6-13,4$ & 20,0 & $17,1-22,8$ & 5,1 & $3,8-6,3$ \\
\hline Teresina & 20,0 & $18,3-21,8$ & 32,3 & $29,0-35,6$ & 9,9 & $8,3-11,6$ \\
\hline Vitória & 17,4 & $15,8-19,1$ & 25,2 & $22,1-28,2$ & 10,9 & $9,2-12,7$ \\
\hline Distrito Federal & 16,3 & $14,7-18,0$ & 25,0 & $22,0-28,0$ & 8,7 & $7,2-10,3$ \\
\hline Total & 16,1 & $15,7-16,4$ & 25,3 & $24,8-25,9$ & 8,1 & $7,8-8,4$ \\
\hline
\end{tabular}

* Percentual ponderado para ajustar a distribuição sócio-demográfica da amostra VIGITEL em cada cidade à distribuição da população adulta da cidade no Censo Demográfico de 2000 e, no caso do conjunto das cidades, para levar em conta o peso populacional de cada cidade. VIGITEL: Vigilância de Fatores de Risco e Proteção para Doenças Crônicas por Inquérito Telefônico. IC95\%: Intervalo de Confiança de 95\%.

* Weighed percentage for adjusting the socio-demographic distribution of VIGITEL's sample in each city to the distribution of the adult population of the 2000 Demographic Census and for the set of cities, to take into account the population weight of each city. VIGITEL: Vigilância de Fatores de Risco e Proteção para Doenças Crônicas por Inquérito Telefônico. IC95\%: 95\% Confidence Interval. 


\section{Excesso de peso}

A freqüência de adultos com excesso de peso nas 27 cidades estudadas foi de $43,0 \%$, variando entre $34,1 \%$ em São Luiz e 48,3\% no Rio de Janeiro. O excesso de peso tendeu a ser mais freqüente em homens do que em mulheres, exceto nas cidades de Recife, Rio Branco, Salvador e São Paulo, onde as freqüências foram semelhantes nos dois sexos. Entre os homens, as maio- res frequiências foram encontradas em cidades do Centro-Sul do país - Cuiabá $(51,4 \%)$, Rio de Janeiro $(52,6 \%)$ e Porto Alegre $(54,2 \%)$ - e as menores em cidades da região Nordeste - Teresina $(42,2 \%)$, Salvador $(41,2 \%)$ e São Luís $(37,2 \%)$. Entre as mulheres, o excesso de peso foi mais freqüente em São Paulo (42,8\%), Rio Branco $(43,1 \%)$ e Rio de Janeiro $(44,4 \%)$, e menos freqüente em Belém (30,9\%), Teresina $(29,5 \%)$ e Palmas $(24,9 \%)$ (Tabela 3$)$.

Tabela 3 - Percentual de adultos (e•18 anos) com excesso de peso*, por sexo, segundo as capitais dos Estados brasileiros e Distrito Federal**. VIGITEL, 2006.

Table 3 - Percentage of overweight adults (e・18 years) ${ }^{*}$, by gender, according to the capitals of Brazilian States and the Federal District **. VIGITEL, 2006.

\begin{tabular}{|c|c|c|c|c|c|c|}
\hline \multirow{3}{*}{ Capitais / DF } & \multirow{2}{*}{\multicolumn{2}{|c|}{ Total }} & \multicolumn{4}{|c|}{ Sexo } \\
\hline & & & \multicolumn{2}{|c|}{ Masculino } & \multicolumn{2}{|c|}{ Feminino } \\
\hline & $\%$ & IC95\% & $\%$ & IC95\% & $\%$ & IC95\% \\
\hline Aracaju & 40,2 & $37,9-42,4$ & 46,2 & $42,5-49,9$ & 34,3 & $31,6-37,1$ \\
\hline Belém & 39,5 & $37,2-41,7$ & 47,8 & $44,2-51,3$ & 30,9 & $28,1-33,7$ \\
\hline Belo Horizonte & 37,1 & $34,9-39,3$ & 43,3 & $39,7-46,8$ & 31,4 & $28,6-34,1$ \\
\hline Boa Vista & 43,0 & $40,7-45,2$ & 49,9 & $46,4-53,4$ & 34,6 & $31,7-37,5$ \\
\hline Campo Grande & 43,2 & $40,9-45,4$ & 49,4 & $45,8-53,0$ & 36,7 & $33,9-39,6$ \\
\hline Cuiabá & 45,0 & $42,7-47,2$ & 51,4 & $48,0-54,9$ & 38,5 & $35,6-41,5$ \\
\hline Curitiba & 43,7 & $41,5-45,9$ & 50,0 & $46,5-53,6$ & 37,7 & $34,9-40,6$ \\
\hline Florianópolis & 40,4 & $38,2-42,6$ & 48,5 & $45,1-52,0$ & 32,2 & $29,4-35,0$ \\
\hline Fortaleza & 42,2 & $39,9-44,5$ & 48,5 & $44,9-52,1$ & 36,2 & $33,3-39,2$ \\
\hline Goiânia & 38,4 & $36,2-40,6$ & 44,8 & $41,2-48,3$ & 32,3 & $29,5-35,0$ \\
\hline João Pessoa & 42,1 & $39,9-44,4$ & 46,7 & $43,2-50,3$ & 37,8 & $34,8-40,7$ \\
\hline Macapá & 41,5 & $39,2-43,7$ & 47,1 & $43,7-50,6$ & 34,7 & $31,8-37,7$ \\
\hline Maceió & 40,2 & $38,0-42,5$ & 44,4 & $41,8-47,9$ & 36,2 & $33,3-39,1$ \\
\hline Manaus & 43,7 & $41,4-46,0$ & 51,3 & $47,9-54,8$ & 35,4 & $32,4-38,4$ \\
\hline Natal & 42,9 & $40,6-45,2$ & 48,8 & $45,2-54,4$ & 37,1 & $34,2-40,0$ \\
\hline Palmas & 36,4 & $34,3-38,6$ & 46,2 & $42,8-49,5$ & 24,9 & $22,3-27,6$ \\
\hline Porto Alegre & 47,9 & $45,7-50,2$ & 54,2 & $50,6-54,9$ & 42,4 & $39,7-45,2$ \\
\hline Porto Velho & 41,8 & $39,6-44,1$ & 46,2 & $42,8-49,6$ & 36,7 & $33,7-39,7$ \\
\hline Recife & 43,3 & $41,0-45,5$ & 45,9 & $42,2-49,5$ & 40,8 & $37,9-43,6$ \\
\hline Rio Branco & 44,2 & $41,9-46,5$ & 45,2 & $41,7-48,8$ & 43,1 & $40,0-46,2$ \\
\hline Rio de Janeiro & 48,3 & $46,0-50,6$ & 52,6 & $49,0-56,3$ & 44,4 & $41,5-47,3$ \\
\hline Salvador & 39,2 & $36,9-41,5$ & 41,2 & $37,7-44,7$ & 37,2 & $34,2-40,1$ \\
\hline São Luís & 34,1 & $31,8-36,3$ & 37,2 & $33,8-40,7$ & 31,0 & $28,1-33,8$ \\
\hline São Paulo & 44,3 & $42,0-46,5$ & 45,8 & $42,2-49,3$ & 42,8 & $39,9-45,7$ \\
\hline Teresina & 35,8 & $33,5-38,0$ & 42,2 & $38,6-47,8$ & 29,5 & $26,7-32,3$ \\
\hline Vitória & 38,5 & $36,3-40,8$ & 45,5 & $41,9-49,1$ & 31,9 & $29,1-34,7$ \\
\hline Distrito Federal & 39,8 & $37,6-42,0$ & 48,1 & $44,6-51,6$ & 31,6 & $29,0-34,3$ \\
\hline Total & 43,0 & $42,6-43,4$ & 47,3 & $46,6-48,0$ & 38,8 & $38,2-39,4$ \\
\hline
\end{tabular}

* Índice de Massa Corporal e $25 \mathrm{~kg} / \mathrm{m}^{2}$. ** Percentual ponderado para ajustar a distribuição sócio-demográfica da amostra VIGITEL em cada cidade à distribuição da população adulta da cidade no Censo Demográfico de 2000 e, no caso do conjunto das cidades, para levar em conta o peso populacional de cada cidade. VIGITEL:Vigilância de Fatores de Risco e Proteção para Doenças Crônicas por Inquérito Telefônico. IC95\%: Intervalo de Confiança de 95\%.

* Body Mass Index e.25 kg/m $\mathrm{m}^{2}$. ** Weighed percentage for adjusting the socio-demographic distribution of VIGITEL's sample in each city to the distribution of the adult population of the 2000 Demographic Census and for the set of cities, to take into account the population weight of each city. VIGITEL:Vigilância de Fatores de Risco e Proteção para Doenças Crônicas por Inquérito Telefônico. IC95\%: 95\% Confidence Interval. 


\section{Consumo de carnes com excesso de gordura}

A freqüência do hábito de consumir carnes com excesso de gordura (carne vermelha gordurosa ou carne de frango com pele sem remoção da gordura visível do alimento) foi de $39,2 \%$ no conjunto da população adulta das 27 cidades, variando entre $26,7 \%$ em Salvador e 53,1\% em Palmas. Em todas as cidades, o consumo de carnes com excesso de gordura foi mais freqüente em homens do que em mulheres. As maiores freqüências entre os homens foram observadas em Cuiabá (62,0\%), Campo Grande (62,5\%) e Palmas $(68,1 \%)$, e as menores em Florianópolis $(45,0 \%)$, Belém (43,6\%) e Salvador $(37,6 \%)$. Situação semelhante é observada entre as mulheres, com maiores freqüências ocorrendo em Belo Horizonte (39,1\%), Campo Grande $(40,6 \%)$ e Cuiabá $(42,2 \%)$, e as menores em Florianópolis (22,8\%), Manaus $(21,7 \%)$ e Salvador (17,5\%) (Tabela 4).

Tabela 4 - Percentual de adultos (e•18 anos) que costumam consumir carnes com excesso de gordura*, por sexo, segundo as capitais dos Estados brasileiros e Distrito Federal**. VIGITEL, 2006.

Table 4 - Percentage of adults (e•18 years) who frequently eat meats with excessive fat*, by gender, according to the capitals of Brazilian States and the Federal District ${ }^{* *}$. VIGITEL, 2006.

\begin{tabular}{|c|c|c|c|c|c|c|}
\hline \multirow{3}{*}{ Capitais / DF } & \multirow{2}{*}{\multicolumn{2}{|c|}{ Total }} & \multicolumn{4}{|c|}{ Sexo } \\
\hline & & & \multicolumn{2}{|c|}{ Masculino } & \multicolumn{2}{|c|}{ Feminino } \\
\hline & $\%$ & IC95\% & $\%$ & IC95\% & $\%$ & IC95\% \\
\hline Aracaju & 38,8 & $36,7-40,9$ & 54,3 & $50,7-57,9$ & 26,1 & $23,7-28,5$ \\
\hline Belém & 34,1 & $32,0-36,2$ & 43,6 & $40,2-47,1$ & 25,9 & $23,4-28,3$ \\
\hline Belo Horizonte & 49,0 & $46,8-51,2$ & 60,6 & $57,2-64,0$ & 39,1 & $36,4-41,9$ \\
\hline Boa Vista & 48,2 & $46,0-50,4$ & 59,6 & $56,3-63,0$ & 36,9 & $34,2-39,6$ \\
\hline Campo Grande & 51,0 & $48,8-53,2$ & 62,5 & $59,1-65,9$ & 40,6 & $37,9-43,3$ \\
\hline Cuiabá & 51,7 & $49,5-53,9$ & 62,0 & $58,7-65,3$ & 42,2 & $39,4-45,0$ \\
\hline Curitiba & 43,0 & $40,8-45,1$ & 54,7 & $51,2-58,2$ & 32,7 & $30,1-35,3$ \\
\hline Florianópolis & 33,3 & $31,3-35,4$ & 45,0 & $41,6-48,4$ & 22,8 & $20,4-25,2$ \\
\hline Fortaleza & 38,4 & $36,2-40,5$ & 48,9 & $45,4-52,4$ & 29,8 & $27,2-32,3$ \\
\hline Goiânia & 47,7 & $45,5-49,9$ & 57,7 & $54,2-61,1$ & 39,0 & $36,3-41,8$ \\
\hline João Pessoa & 36,9 & $34,8-39,1$ & 50,5 & $47,0-54,0$ & 25,9 & $23,4-28,3$ \\
\hline Macapá & 42,2 & $40,1-44,4$ & 54,3 & $51,0-57,7$ & 30,8 & $28,2-33,5$ \\
\hline Maceió & 41,5 & $39,3-43,6$ & 53,8 & $50,3-57,3$ & 31,2 & $28,6-33,8$ \\
\hline Manaus & 34,4 & $32,3-36,5$ & 48,2 & $44,8-51,6$ & 21,7 & $19,4-24,1$ \\
\hline Natal & 34,8 & $32,7-36,9$ & 45,9 & $42,4-49,4$ & 25,6 & $23,2-28,0$ \\
\hline Palmas & 53,1 & $50,9-55,3$ & 68,1 & $65,0-71,2$ & 37,9 & $35,1-40,7$ \\
\hline Porto Alegre & 40,4 & $38,2-42,5$ & 53,3 & $49,6-56,9$ & 29,8 & $27,3-32,3$ \\
\hline Porto Velho & 41,4 & $39,3-43,6$ & 53,1 & $49,7-56,4$ & 30,1 & $27,5-32,7$ \\
\hline Recife & 38,8 & $36,7-40,9$ & 49,7 & $46,1-53,4$ & 30,0 & $27,5-32,5$ \\
\hline Rio Branco & 43,4 & $41,2-45,5$ & 50,5 & $47,1-54,0$ & 36,8 & $34,1-39,5$ \\
\hline Rio de Janeiro & 35,0 & $33,0-37,1$ & 45,3 & $41,8-48,9$ & 26,4 & $24,0-28,9$ \\
\hline Salvador & 26,7 & $24,7-28,6$ & 37,6 & $34,3-41,0$ & 17,5 & $15,4-19,6$ \\
\hline São Luís & 36,4 & $34,3-38,5$ & 49,0 & $45,5-52,4$ & 25,9 & $23,5-28,4$ \\
\hline São Paulo & 41,0 & $38,8-43,1$ & 54,2 & $50,8-57,8$ & 29,4 & $26,9-32,0$ \\
\hline Teresina & 35,8 & $33,7-37,9$ & 47,2 & $43,7-50,7$ & 26,4 & $24,0-28,9$ \\
\hline Vitória & 43,3 & $41,1-45,5$ & 54,1 & $50,6-57,6$ & 34,2 & $31,6-36,8$ \\
\hline Distrito Federal & 40,9 & $38,7-43,0$ & 55,5 & $52,0-59,0$ & 28,0 & $25,5-30,5$ \\
\hline Total & 39,2 & $38,8-39,7$ & 51,2 & $50,6-51,9$ & 29,0 & $28,5-29,5$ \\
\hline
\end{tabular}

* Adultos que consomem carne vermelha gordurosa ou frango com pele sem remover a gordura visível do alimento.

** Percentual ponderado para ajustar a distribuição sócio-demográfica da amostra VIGITEL em cada cidade à distribuição da população adulta da cidade no Censo Demográfico de 2000 e, no caso do conjunto das cidades, para levar em conta o peso populacional de cada cidade. VIGITEL: Vigilância de Fatores de Risco e Proteção para Doenças Crônicas por Inquérito Telefônico. IC95\%: Intervalo de Confiança de 95\%.

${ }^{*}$ Adults who eat fat red meat or chicken with skin without removing visible fat from food. ${ }^{* *}$ Weighed percentage for adjusting the socio-demographic distribution of VIGITEL's sample in each city to the distribution of the adult population of the 2000 Demographic Census and for the set of cities, to take into account the population weight of each city. VIGITEL:Vigilância de Fatores de Risco e Proteção para Doenças Crônicas por Inquérito Telefônico. IC95\%: 95\% Confidence Interval. 


\section{Sedentarismo}

A freqüência de indivíduos sedentários (indivíduos que não praticam qualquer atividade física no lazer, não realizam esforços físicos intensos no trabalho, não se deslocam para o trabalho a pé ou de bicicleta, e não são responsáveis pela "limpeza pesada” de suas casas) foi de $29,2 \%$ no conjunto da população adulta das 27 cidades estudadas, variando entre $21,6 \% \mathrm{em}$ Boa Vista e 35,1\% em Natal. De modo geral, a inatividade física tendeu a ser bem mais freqüente no sexo masculino do que no sexo feminino. Entre os homens, as maiores freqüências foram observadas em cidades da região Nordeste - Maceió $(43,9 \%)$, Natal $(46,8 \%)$ e João Pessoa $(47,3 \%)$ - e as menores em cidades da região Norte - Palmas (33,3\%), Porto Velho $(31,7 \%)$ e Boa Vista (28,6\%). Situação semelhante é vista entre as mulheres, com as maiores freqüências novamente observadas em cidades da região Nordeste - João Pessoa (25,0\%), Natal $(25,4 \%)$ e Aracaju $(26,5 \%)$ - e as menores em cidades da região Norte - Porto Velho (16,6\%), Manaus $(14,8 \%)$ e Boa Vista (14,6\%) (Tabela 5).

Tabela 5 - Percentual de adultos (e•18 anos) fisicamente inativos*, por sexo, segundo as capitais dos Estados brasileiros e Distrito Federal*** VIGITEL, 2006.

Table 5 - Percentage of physically inactive adults (e•18 years)*, by gender, according to the capitals of Brazilian States and the Federal District**. VIGITEL, 2006.

\begin{tabular}{|c|c|c|c|c|c|c|}
\hline \multirow{3}{*}{ Capitais / DF } & \multirow{2}{*}{\multicolumn{2}{|c|}{ Total }} & \multicolumn{4}{|c|}{ Sexo } \\
\hline & & & \multicolumn{2}{|c|}{ Masculino } & \multicolumn{2}{|c|}{ Feminino } \\
\hline & $\%$ & IC95\% & $\%$ & IC95\% & $\%$ & IC95\% \\
\hline Aracaju & 33,0 & $31,0-35,1$ & 40,9 & $37,3-44,4$ & 26,5 & $24,1-28,9$ \\
\hline Belém & 28,0 & $26,1-30,0$ & 37,7 & $34,4-44,4$ & 19,7 & $17,5-21,9$ \\
\hline Belo Horizonte & 30,6 & $28,6-32,6$ & 42,5 & $39,0-46,0$ & 20,5 & $18,2-22,7$ \\
\hline Boa Vista & 21,6 & $19,8-23,4$ & 28,6 & $25,5-31,7$ & 14,6 & $12,6-16,6$ \\
\hline Campo Grande & 27,5 & $25,5-29,4$ & 35,1 & $31,7-38,4$ & 20,6 & $18,3-22,9$ \\
\hline Cuiabá & 28,4 & $26,4-30,3$ & 37,2 & $33,9-40,5$ & 20,3 & $18,0-22,6$ \\
\hline Curitiba & 27,3 & $25,3-29,2$ & 37,2 & $33,8-40,6$ & 18,5 & $16,4-20,7$ \\
\hline Florianópolis & 27,7 & $25,7-29,6$ & 33,4 & $30,1-36,6$ & 22,5 & $20,2-24,9$ \\
\hline Fortaleza & 31,4 & $29,4-33,4$ & 42,9 & $39,5-46,4$ & 22,0 & $19,7-24,3$ \\
\hline Goiânia & 27,9 & $25,9-29,8$ & 40,1 & $36,7-43,6$ & 17,2 & $15,1-19,3$ \\
\hline João Pessoa & 35,0 & $32,9-37,1$ & 47,3 & $43,8-50,8$ & 25,0 & $22,6-27,4$ \\
\hline Macapá & 25,9 & $24,0-27,8$ & 35,3 & $32,1-38,6$ & 17,1 & $14,9-19,2$ \\
\hline Maceió & 31,9 & $29,9-34,0$ & 43,9 & $40,4-47,4$ & 21,9 & $19,6-24,3$ \\
\hline Manaus & 25,3 & $23,4-27,2$ & 36,6 & $33,3-39,8$ & 14,8 & $12,8-16,9$ \\
\hline Natal & 35,1 & $33,0-37,2$ & 46,8 & $43,3-50,4$ & 25,4 & $23,0-27,8$ \\
\hline Palmas & 25,7 & $23,8-27,6$ & 33,3 & $30,1-36,4$ & 18,0 & $15,8-20,3$ \\
\hline Porto Alegre & 29,7 & $27,7-31,7$ & 37,1 & $33,6-40,6$ & 23,6 & $21,3-25,9$ \\
\hline Porto Velho & 24,1 & $22,2-25,9$ & 31,7 & $28,6-34,9$ & 16,6 & $14,5-18,7$ \\
\hline Recife & 30,9 & $28,9-32,9$ & 40,7 & $37,1-44,3$ & 23,0 & $20,7-25,3$ \\
\hline Rio Branco & 30,4 & $28,4-32,4$ & 39,5 & $36,2-42,9$ & 22,1 & $19,7-24,4$ \\
\hline Rio de Janeiro & 30,3 & $28,3-32,3$ & 40,7 & $37,2-44,2$ & 21,7 & $19,4-23,9$ \\
\hline Salvador & 28,0 & $26,0-29,9$ & 37,4 & $34,0-40,8$ & 20,1 & $17,9-22,4$ \\
\hline São Luís & 26,8 & $24,8-28,7$ & 35,7 & $32,4-39,1$ & 19,3 & $17,1-21,5$ \\
\hline São Paulo & 27,7 & $25,8-29,7$ & 39,7 & $36,3-43,5$ & 17,3 & $15,2-19,4$ \\
\hline Teresina & 30,0 & $28,0-32,0$ & 42,3 & $38,8-45,8$ & 19,9 & $17,7-22,2$ \\
\hline Vitória & 30,8 & $28,8-32,8$ & 39,3 & $35,9-42,8$ & 23,6 & $21,2-25,9$ \\
\hline Distrito Federal & 32,3 & $30,3-34,3$ & 41,6 & $38,1-45,0$ & 24,1 & $21,7-26,5$ \\
\hline Total & 29,2 & $28,8-29,6$ & 39,8 & $39,1-40,4$ & 20,1 & $19,7-20,5$ \\
\hline
\end{tabular}

* Adultos que não praticaram qualquer atividade física no lazer nos últimos três meses e que não realizam esforços físicos intensos no trabalho não se deslocam para o trabalho caminhando ou de bicicleta e não são responsáveis pela limpeza pesada de suas casas. ** Percentual ponderado para ajustar a distribuição sócio-demográfica da amostra VIGITEL em cada cidade à distribuição da população adulta da cidade no Censo Demográfico de 2000 e, no caso do conjunto das cidades, para levar em conta o peso populacional de cada cidade. VIGITEL:Vigilância de Fatores de Risco e Proteção para Doenças Crônicas por Inquérito Telefônico. IC $95 \%$ : Intervalo de Confiança de $95 \%$.

${ }^{*}$ Adults who have not practiced any leisure physical activity in the past three months and who have not done intense physical work, have not gone to work on foot or riding a bicycle or who are not responsible for heavy housecleaning in their homes. ** Weighed percentage for adjusting the socio-demographic distribution of VIGITEL's sample in each city to the distribution of the adult population of the 2000 Demographic Census and for the set of cities, to take into account the population weight of each city. VIGITEL: Vigilância de Fatores de Risco e Proteção para Doenças Crônicas por Inquérito Telefônico. IC95\%: 95\% Confidence Interval. 


\section{Consumo regular de frutas e hortaliças}

A freqüência de indivíduos que consomem regularmente frutas e hortaliças (consumo dos dois grupos de alimentos em cinco ou mais dias da semana) foi de $23,9 \%$ no conjunto da população adulta das 27 cidades, variando entre 7,3\% em Macapá e $38,6 \%$ em Porto Alegre (38,6\%). Em todas as cidades, o consumo regular de frutas e hortaliças foi mais freqüente em mulheres do que em homens. Entre os homens, as maio- res freqüências foram observadas em cidades da região Sul - Florianópolis (26,6\%), Curitiba $(28,1 \%)$ e Porto Alegre $(29,7 \%)$ e as menores em cidades da região Norte - Boa Vista (9,4\%), Belém (6,4\%) e Macapá $(5,4 \%)$. Situação semelhante ocorre entre as mulheres, com as maiores freqüências observadas em cidades da região Sul - Curitiba $(40,7 \%)$, Florianópolis $(43,9 \%)$ e Porto Alegre $(46,0 \%)$ - e as menores em cidades da região Norte - Boa Vista (14,2\%), Manaus $(12,0 \%)$ e Macapá $(9,1 \%)$ (Tabela 6).

Tabela 6 - Percentual de adultos (e•18 anos) que consomem frutas e hortaliças cinco ou mais dias por semana, por sexo, segundo as capitais dos Estados brasileiros e Distrito Federal*. VIGITEL, 2006.

Table 6 - Percentage of adults (e•18 years) who eat fruit and vegetables five or more days a week, by gender, according to the capitals of Brazilian States and the Federal District *. VIGITEL, 2006.

\begin{tabular}{|c|c|c|c|c|c|c|}
\hline \multirow{3}{*}{ Capitais / DF } & \multirow{2}{*}{\multicolumn{2}{|c|}{ Total }} & \multicolumn{4}{|c|}{ Sexo } \\
\hline & & & \multicolumn{2}{|c|}{ Masculino } & \multicolumn{2}{|c|}{ Feminino } \\
\hline & $\%$ & IC95\% & $\%$ & IC95\% & $\%$ & IC95\% \\
\hline Aracaju & 24,2 & $22,3-26,0$ & 18,7 & $15,9-21,5$ & 28,6 & $26,2-31,1$ \\
\hline Belém & 10,6 & $9,3-12,0$ & 6,4 & $4,7-8,1$ & 14,3 & $12,3-16,2$ \\
\hline Belo Horizonte & 26,7 & $24,8-28,6$ & 21,6 & $18,7-24,5$ & 31,0 & $28,5-33,6$ \\
\hline Boa Vista & 11,8 & $10,4-13,2$ & 9,4 & $7,4-11,5$ & 14,2 & $12,2-16,2$ \\
\hline Campo Grande & 28,9 & $27,0-30,9$ & 20,8 & $17,9-23,1$ & 36,4 & $33,7-39,0$ \\
\hline Cuiabá & 21,7 & $19,9-23,5$ & 15,4 & $12,9-17,5$ & 27,4 & $24,9-29,9$ \\
\hline Curitiba & 34,8 & $32,7-36,9$ & 28,1 & $24,9-31,3$ & 40,7 & $37,9-43,4$ \\
\hline Florianópolis & 35,7 & $33,6-37,8$ & 26,6 & $23,6-29,6$ & 43,9 & $41,1-46,7$ \\
\hline Fortaleza & 19,4 & $17,7-21,1$ & 16,7 & $14,1-19,3$ & 21,6 & $19,3-23,9$ \\
\hline Goiânia & 27,7 & $25,8-29,7$ & 17,4 & $14,7-20,0$ & 36,8 & $34,1-34,5$ \\
\hline João Pessoa & 25,9 & $24,0-27,8$ & 21,1 & $18,2-24,0$ & 29,8 & $27,2-32,3$ \\
\hline Macapá & 7,3 & $6,1-8,4$ & 5,4 & $3,8-6,9$ & 9,1 & $7,4-10,7$ \\
\hline Maceió & 19,0 & $17,3-20,7$ & 13,9 & $11,5-16,4$ & 23,3 & $20,9-25,6$ \\
\hline Manaus & 11,3 & $9,9-12,7$ & 10,5 & $8,4-12,5$ & 12,0 & $10,1-13,9$ \\
\hline Natal & 22,1 & $20,3-23,9$ & 15,7 & $13,1-18,3$ & 27,4 & $24,9-29,8$ \\
\hline Palmas & 22,7 & $20,9-24,6$ & 12,6 & $10,4-14,8$ & 33,0 & $30,3-35,7$ \\
\hline Porto Alegre & 38,6 & $36,5-40,7$ & 29,7 & $26,3-33,0$ & 46,0 & $43,2-48,7$ \\
\hline Porto Velho & 17,6 & $15,9-19,2$ & 13,5 & $11,2-15,8$ & 21,5 & $19,2-23,9$ \\
\hline Recife & 20,5 & $18,7-22,3$ & 17,1 & $14,3-19,8$ & 23,3 & $21,0-25,6$ \\
\hline Rio Branco & 14,5 & $13,0-16,1$ & 9,8 & $7,8-11,8$ & 18,9 & $16,7-21,1$ \\
\hline Rio de Janeiro & 20,9 & $19,2-22,7$ & 16,0 & $13,4-18,7$ & 25,0 & $22,6-27,4$ \\
\hline Salvador & 17,6 & $15,9-19,2$ & 13,3 & $10,9-15,7$ & 21,1 & $18,8-23,4$ \\
\hline São Luís & 16,2 & $14,5-17,8$ & 13,2 & $10,9-15,6$ & 18,6 & $16,4-20,7$ \\
\hline São Paulo & 26,8 & $24,9-28,8$ & 17,9 & $15,2-20,6$ & 34,7 & $32,0-37,3$ \\
\hline Teresina & 17,9 & $16,2-19,6$ & 15,3 & $12,8-17,9$ & 20,0 & $17,7-22,2$ \\
\hline Vitória & 28,2 & $26,3-30,2$ & 24,1 & $21,1-27,1$ & 31,7 & $29,1-34,3$ \\
\hline Distrito Federal & 30,8 & $28,8-32,9$ & 24,8 & $21,8-27,8$ & 36,1 & $33,4-38,8$ \\
\hline Total & 23,9 & $23,5-24,2$ & 17,8 & $17,3-18,3$ & 29,1 & $28,6-29,6$ \\
\hline
\end{tabular}

* Percentual ponderado para ajustar a distribuição sócio-demográfica da amostra VIGITEL em cada cidade à distribuição da população adulta da cidade no Censo Demográfico de 2000 e, no caso do conjunto das cidades, para levar em conta o peso populacional de cada cidade. VIGITEL: Vigilância de Fatores de Risco e Proteção para Doenças Crônicas por Inquérito Telefônico. IC95\%: Intervalo de Confiança de 95\%.

*Weighed percentage for adjusting the socio-demographic distribution of VIGITEL's sample in each city to the distribution of the adult population of the 2000 Demographic Census and for the set of cities, to take into account the population weight of each city. VIGITEL: Vigilância de Fatores de Risco e Proteção para Doenças Crônicas por Inquérito Telefônico.IC95\%:95\% Confidence Interval. 


\section{Atividade física suficiente no lazer}

A freqüência de indivíduos que praticam atividade física suficiente no lazer (prática de pelo menos 30 minutos diários de atividades leves ou moderadas em cinco ou mais dias da semana ou pelo menos 20 minutos de atividades vigorosas em três ou mais dias da semana) foi de $14,9 \%$ no conjunto da população adulta das 27 cidades, variando entre 10,5\% em São Paulo e $21,5 \%$ no Distrito Federal. Em todas as cidades, exceto em Campo Grande, mais homens do que mulheres praticam atividade física suficiente no lazer. Entre os homens, as maiores freqüências foram encontradas em Fortaleza (22,7\%), no Distrito Federal $(24,7 \%)$ e em Macapá $(25,6 \%)$ e as menores em Palmas (16,4\%), Campo Grande (15,4\%) e São Paulo (12,5\%). Entre as mulheres, as maiores freqüências foram observadas em Vitória (15,8\%), Campo Grande $(17,2 \%)$ e Distrito Federal $(18,7 \%)$ e as menores em São Luiz (9,0\%), Teresina $(8,9 \%)$ e São Paulo (8,8\%) (Tabela 7$)$.

Tabela 7 - Percentual de adultos (e•18 anos) que praticam atividade física suficiente no lazer*, por sexo, segundo as capitais dos Estados brasileiros e Distrito Federal ${ }^{* *}$. VIGITEL, 2006.

Table 7 - Percentage of adults (e•18 years) who had enough leisure exercise*, by gender, according to the capitals of Brazilian States and the Federal District **. VIGITEL, 2006.

\begin{tabular}{|c|c|c|c|c|c|c|}
\hline \multirow{3}{*}{ Capitais / DF } & \multirow{2}{*}{\multicolumn{2}{|c|}{ Total }} & \multicolumn{4}{|c|}{ Sexo } \\
\hline & & & \multicolumn{2}{|c|}{ Masculino } & \multicolumn{2}{|c|}{ Feminino } \\
\hline & $\%$ & IC95\% & $\%$ & IC95\% & $\%$ & IC95\% \\
\hline Aracaju & 16,3 & $14,6-17,9$ & 20,2 & $17,3-23,1$ & 13,0 & $11,2-14,9$ \\
\hline Belém & 16,6 & $15,0-18,2$ & 20,3 & $17,5-23,1$ & 13,4 & $11,5-15,3$ \\
\hline Belo Horizonte & 15,9 & $14,3-17,5$ & 18,6 & $15,9-21,3$ & 13,5 & $11,6-15,5$ \\
\hline Boa Vista & 17,3 & $15,6-18,9$ & 22,5 & $19,6-25,4$ & 12,1 & $10,3-14,0$ \\
\hline Campo Grande & 16,4 & $14,8-18,0$ & 15,4 & $12,9-17,9$ & 17,2 & $15,1-19,3$ \\
\hline Cuiabá & 16,9 & $15,3-18,5$ & 20,1 & $17,4-22,8$ & 14,0 & $12,0-16,0$ \\
\hline Curitiba & 16,5 & $14,8-18,1$ & 21,0 & $18,1-23,8$ & 12,5 & $10,7-14,4$ \\
\hline Florianópolis & 16,3 & $14,7-18,0$ & 19,8 & $17,0-22,5$ & 13,3 & $11,3-15,2$ \\
\hline Fortaleza & 18,0 & $16,3-19,7$ & 22,7 & $19,8-25,6$ & 14,2 & $12,2-16,1$ \\
\hline Goiânia & 15,6 & $14,0-17,2$ & 17,2 & $14,6-19,9$ & 14,1 & $12,2-16,1$ \\
\hline João Pessoa & 15,8 & $14,2-17,4$ & 18,0 & $15,3-20,7$ & 13,9 & $12,0-15,9$ \\
\hline Macapá & 18,2 & $16,5-19,9$ & 25,6 & $22,7-28,6$ & 11,1 & $9,3-12,9$ \\
\hline Maceió & 16,6 & $15,0-18,3$ & 20,5 & $17,7-23,4$ & 13,4 & $11,5-15,3$ \\
\hline Manaus & 14,9 & $13,3-16,4$ & 18,8 & $16,1-21,4$ & 11,3 & $9,4-13,1$ \\
\hline Natal & 16,4 & $14,7-18,0$ & 18,8 & $16,0-21,6$ & 14,3 & $12,4-16,3$ \\
\hline Palmas & 16,1 & $14,5-17,7$ & 16,4 & $13,9-18,8$ & 15,8 & $13,7-17,9$ \\
\hline Porto Alegre & 17,9 & $16,2-19,5$ & 21,9 & $18,9-24,9$ & 14,6 & $12,6-16,5$ \\
\hline Porto Velho & 15,5 & $13,9-17,1$ & 19,2 & $16,6-21,9$ & 11,9 & $10,0-13,8$ \\
\hline Recife & 14,7 & $13,1-16,2$ & 19,4 & $16,5-22,3$ & 10,9 & $9,2-12,6$ \\
\hline Rio Branco & 14,7 & $13,2-16,3$ & 18,0 & $15,4-20,7$ & 11,7 & $9,9-13,5$ \\
\hline Rio de Janeiro & 16,4 & $14,8-18,0$ & 21,8 & $18,9-24,8$ & 11,8 & $10,0-13,6$ \\
\hline Salvador & 14,6 & $13,1-16,2$ & 18,4 & $15,6-21,1$ & 11,5 & $9,8-13,3$ \\
\hline São Luís & 13,6 & $12,1-15,1$ & 19,1 & $16,4-21,9$ & 9,0 & $7,4-10,6$ \\
\hline São Paulo & 10,5 & $9,2-11,9$ & 12,5 & $10,2-14,8$ & 8,8 & $7,2-10,4$ \\
\hline Teresina & 12,6 & $11,1-14,0$ & 17,1 & $14,5-19,8$ & 8,9 & $7,3-10,4$ \\
\hline Vitória & 17,6 & $16,0-19,3$ & 20,0 & $17,1-22,8$ & 15,6 & $13,6-17,6$ \\
\hline Distrito Federal & 21,5 & $19,7-23,3$ & 24,7 & $21,7-27,7$ & 18,8 & $16,6-20,9$ \\
\hline Total & 14,9 & $14,6-15,2$ & 18,3 & $17,8-18,8$ & 11,9 & $11,6-12,3$ \\
\hline
\end{tabular}




\section{Discussão}

A discussão deste artigo focalizará a potencial relevância dos indicadores do VIGITEL, o desempenho do sistema e as perspectivas para sua continuidade e aperfeiçoamento.

\section{Indicadores do sistema}

Estimativas da OMS revelam que os indicadores do VIGITEL apresentados neste artigo correspondem ou estão associados a fatores de grande impacto com relação ao perfil de morbimortalidade descrito para a região epidemiológica das Américas onde se encontra o Brasil. Na relação de fatores aos quais se atribui maior número de anos de vida saudável perdidos por doença ou morte precoce naquela região, encontram-se o consumo excessivo de álcool (primeiro lugar), o excesso de peso (segundo lugar), o tabagismo (quarto lugar), a hipercolesterolemia (quinto lugar); o consumo insuficiente de frutas e hortaliças (oitavo lugar) e a inatividade física (décimo lugar) ${ }^{1}$.

Note-se, ainda, que os indicadores divulgados neste artigo representam uma pequena fração dos indicadores que podem ser construídos a partir dos dados coletados pelo VIGITEL. No caso do tema tabagismo, por exemplo, além da freqüência de fumantes pode-se estimar a freqüência de ex-fumantes, a taxa de cessação, a intensidade do hábito de fumar e a idade do início deste hábito. O mesmo vale para os demais temas investigados pelo sistema: consumo de bebidas alcoólicas, características do consumo alimentar e dos padrões de atividade física. O VIGITEL disponibiliza, ainda, indicadores sobre temas não focalizados neste artigo, como freqüência de diagnóstico médico de hipertensão arterial, diabetes e dislipidemias, e (a partir de 2007) freqüência e intensidade de exposição à luz solar e realização de exame de Papanicolau e mamografia.

\section{Desempenho do sistema}

O desempenho do VIGITEL será considerado com relação a outros sistemas de vigilância que empregam entrevistas telefônicas e com relação a inquéritos domiciliares tradicionais sobre fatores de risco para DCNTs. No primeiro caso, será utilizado como referência o sistema americano de vigilância por entrevistas telefônicas - o "Behavioral Risk Factor Surveillance System - BRFSS”. O BRFSS, criado pelo Centro de Controle de Doenças dos Estados Unidos em 1981, é o sistema de vigilância por entrevista telefônica mais antigo e de maior envergadura de todo o mundo. Foi implantado inicialmente em 29 unidades da federação americana e, desde 1994, funciona regularmente em todos os 50 Estados, na capital federal e nos três territórios americanos ${ }^{10}$. A título de referência para inquéritos domiciliares tradicionais, será utilizado o Inquérito Domiciliar sobre Comportamento de Risco e Morbidade Referida de Doenças e Agravos não Transmissíveis realizado em 20022003 pela Secretaria de Vigilância em Saúde e Instituto Nacional do Câncer (SVS/ INCA). Este inquérito, doravante denominado SVS/INCA, continha questões semelhantes às empregadas pelo VIGITEL, e foi aplicado em amostras probabilísticas dos domicílios das capitais de 15 Estados brasileiros e do Distrito Federal ${ }^{11}$.

A principal limitação de todo sistema de vigilância por entrevistas telefônicas refere-se à exclusão de indivíduos que residem em domicílios sem telefone. A cobertura da rede de telefonia fixa no Brasil, embora tenha crescido nos últimos anos, não é evidentemente universal, podendo ser particularmente baixa em cidades economicamente menos desenvolvidas e nos estratos de menor nível socioeconômico. A única fonte recente de dados de base domiciliar que permite estimar a cobertura da rede de telefonia fixa nas 27 cidades cobertas pelo VIGITEL é a Pesquisa de Or- 
çamentos Familiares (POF) realizada pelo IBGE no período de 2002-2003. Estimativas calculadas a partir dessa pesquisa indicam que $66,4 \%$ do conjunto dos domicílios das 27 cidades declararam despesa com serviço de telefonia fixa, variando esta proporção de 33,7\% em Macapá a 79,4\% no Distrito Federal. Assim calculada, a cobertura da rede de telefonia fixa foi $31,4 \%$, $55,4 \%, 70,9 \%$ e, $80,6 \%$ e $89,9 \%$, respectivamente, para cada um dos quintos da distribuição da renda familiar per capita do conjunto dos domicílios das 27 cidades $^{12}$.

Embora nenhum método direto de compensação para a fração de domicílios não servidos por telefone em cada cidade ou em cada estrato populacional seja empregado pelo sistema VIGITEL, os pesos pós-estratificação aplicados aos indivíduos entrevistados pelo sistema podem corrigir, ao menos parcialmente, vieses determinados pela não cobertura universal da rede telefônica. Como se viu, tais pesos corrigem a sub- ou super-representação de estratos sociodemográficos na amostra do sistema VIGITEL, tendo como referência a composição sociodemográfica da população adulta de cada cidade no mais recente Censo Demográfico. Note-se, todavia, que esta correção apenas "aproxima” as estimativas geradas pelo sistema das estimativas que seriam observadas caso a cobertura da rede telefônica fosse universal ou não apresentasse qualquer diferença entre estratos populacionais. A aproximação será tanto maior quanto mais decisiva for a influência do sexo, idade e nível de escolaridade sobre a freqüência dos eventos de interesse do sistema, e quanto maior for a semelhança entre o comportamento de indivíduos de mesmo gênero, idade e nível de escolaridade servidos e não servidos por linhas telefônicas. Por outro lado, a aplicação dos pesos pós-estratificação atenua problemas decorrentes de diferenças entre os estratos sociodemográficos tanto na cobertura da rede telefônica quanto nas taxas de resposta e de recusas das entrevistas. Finalmente, além de corrigir, a cada ano, a sub- ou super-represen- tação de estratos sociodemográficos, a aplicação de pesos pós-estratificação possibilita séries históricas de indicadores já ajustadas para variações temporais na composição sociodemográfica dos entrevistados, as quais serão bastante prováveis no caso de haver mudanças na cobertura do serviço de telefonia ao longo dos anos.

O sistema americano BRFSS emprega igualmente pesos pós-estratificação para levar em conta diferenciais sociodemográficos existentes tanto na cobertura do serviço telefônico quanto nas taxas de sucesso das entrevistas. Como no VIGITEL, os pesos pósestratificação empregados pelo BRFSS levam em conta o sexo e a idade dos entrevistados, substituindo nível de escolaridade por raça/ etnia $^{13}$.

Outro aspecto crucial da etapa de amostragem que pode limitar a qualidade das estimativas de um sistema de vigilância por entrevistas telefônicas é o grau de completude do cadastro de linhas telefônicas residenciais a partir do qual se faz o sorteio das linhas. Com a exceção do Distrito Federal, onde, em 2006, foram consideradas por equívoco apenas quatro áreas administrativas, os cadastros empregados pelo VIGITEL aparentam ser virtualmente universais. Fala a favor dessa hipótese o fato de os cadastros serem fornecidos pela única empresa de telefonia fixa que serve a cidade ou, em alguns poucos casos, pela empresa que detém a grande maioria dos assinantes de linhas fixas residenciais. Note-se, ainda, que os cadastros empregados pelo VIGITEL incluem todos os assinantes residenciais do serviço telefônico, e não apenas os que autorizam a publicidade do seu número em catálogos telefônicos (os cadastros são fornecidos sem o nome do assinante). As vantagens do sistema VIGITEL sobre o sistema americano neste caso são evidentes, pois os cadastros disponíveis para o BRFSS freqüentemente correspondem a catálogos que listam apenas parte dos assinantes das linhas residenciais $^{14,15}$.

A disponibilidade de um cadastro informatizado, estratificado por região de moradia e específico para linhas telefônicas 
residenciais, permitiu que o VIGITEL utilizasse para sorteio das linhas telefônicas procedimento de amostragem bastante simples, tradicional e confiável: amostragem sistemática por estratos ${ }^{16}$. Para sorteio do usuário da linha telefônica a ser entrevistado empregouse procedimento igualmente simples e confiável, qual seja o sorteio informatizado a partir de seqüências aleatórias de números ${ }^{17}$. Em face da já mencionada insuficiente completude dos cadastros de linhas telefônicas residenciais, o BRFSS é obrigado a empregar procedimentos bastante mais complexos de amostragem que incluem uma etapa prévia de sorteio de prefixos telefônicos para estudo da proporção de linhas residenciais nestes prefixos e de seleção de prefixos com um maior potencial de conter linhas residenciais. Além de implicar um número muito maior de ligações telefônicas, esses procedimentos exigem o emprego de fatores adicionais de ponderação para não comprometer a representatividade final da amostra obtida ${ }^{18}$. Em seu início, o sistema BRFSS sorteava para entrevista o usuário da linha telefônica cuja data de aniversário fosse mais próxima do momento da entrevista, mas este procedimento foi substituído pelo uso de seqüências aleatórias de números ${ }^{14}$. Em pré-testes do VIGITEL, notamos que o procedimento de sorteio atrelado a datas de aniversário tomava muito tempo e nem sempre era bem compreendido pelo entrevistado ${ }^{19}$.

Outros dois aspectos que influenciam a qualidade das estimativas de sistemas de vigilância que empregam entrevistas telefônicas são as taxa de resposta e de recusas. Nos dois casos, o desempenho do VIGITEL tendeu a ser melhor do que o do sistema americano BRFSS. Em 2006, a taxa de resposta do sistema americano foi de $51,4 \%$, variando (nos Estados) entre 35,1\% e $66 \%$ - contra $71,1 \%$ no VIGITEL, variando (nas cidades) entre $64,4 \%$ e $81,0 \%$. No mesmo ano, a taxa de recusas no sistema americano foi de $15,3 \%$, variando entre $8,9 \%$ e $22,5 \%$ - contra $9,1 \%$ no VIGITEL, variando entre $5,4 \%$ e $15,0 \%$. Taxas análogas de resposta e de recusas não são imediatamente calculáveis a partir dos dados publicados do inquérito domiciliar SVS/ INCA $^{11}$. Entretanto, considerando-se o percentual de domicílios e os moradores elegíveis que foram efetivamente estudados nesse inquérito, chega-se a valores próximos de $80 \%$ para a taxa de resposta e de $9 \%$ para a taxa de recusa, indicando desempenho um pouco melhor do que o VIGITEL no primeiro caso e semelhança no segundo.

O baixo custo e a extrema agilidade são vantagens naturais de qualquer sistema de vigilância baseado em entrevistas telefônicas. O custo total de realização das 54.369 entrevistas realizadas pelo VIGITEL em 2006 foi de R\$31,15 por entrevista (Secretaria de Vigilância em Saúde do Ministério da Saúde - SVS/MS, Comunicação pessoal). O custo médio por entrevista telefônica realizada pelo sistema americano BRFSS é estimado em 25-30 dólares (ou cerca de $\mathrm{R} \$ 60,00$ ), sendo este custo duas a cinco vezes inferior ao custo médio de entrevistas domiciliares realizadas nos Estados Unidos ${ }^{20}$. O mesmo custo por entrevista do inquérito domiciliar SVS/INCA foi de cerca de R\$ 147,00 por entrevista (SVS/MS, Comunicação pessoal). Além de ser relativamente pouco dispendioso, o VIGITEL se mostrou extremamente ágil: todo o processo de sorteio, aprazamento e realização das 54.369 entrevistas nas 27 cidades foi realizado em um período de cinco meses e um relatório completo do sistema, com tabulações específicas para cada cidade, foi divulgado nacionalmente 68 dias após a conclusão da última entrevista ${ }^{12}$.

\section{Continuidade e aperfeiçoamento do sistema}

São promissoras as perspectivas de continuidade do VIGITEL. Primeiramente, deve-se dizer que ele é parte integrante do Sistema Nacional de Vigilância de Doenças Crônicas do Ministério da Saúde. Seu relativo bom desempenho, baixo custo e grande agilidade, comentados anteriormente, são fatores que certamente favorecerão sua manutenção. Assegurando-se recursos para 
a operação contínua do VIGITEL (a coleta de dados relativa a 2007 já havia se iniciado quando este artigo estava sendo escrito), em pouco tempo haverá séries históricas dos indicadores, o que aumentará sua utilidade, seja para indicar prioridades para políticas públicas de controle das DCNTs, seja para avaliar a efetividade das ações já implementadas, contribuindo, assim, também para a sua perenidade.

Dentre as atividades planejadas ou em andamento para o aperfeiçoamento do VIGITEL, destacam-se: a operação contínua do sistema com entrevistas realizadas ao longo dos doze meses de cada ano; a realização de estudos sobre a confiabilidade e a validade de indicadores (estudo sobre a confiabilidade e validade de indicadores do consumo alimentar e da atividade física já vem sendo executado na cidade de São Paulo); o desenvolvimento de aplicativo eletrônico que permita a realização de tabulações selecionadas dos bancos de dados do sistema por usuários da Internet; a eventual incorporação de novos itens no questionário com a possível identificação de itens que poderiam ser perguntados apenas em anos pares ou ímpares; o desenvolvimento de módulos de questões que aprofundariam determinados temas do questionário; e o treinamento de recursos humanos no manejo dos bancos de dados do sistema (o treinamento de equipes das secretarias municipais de saúde das 27 cidades envolvidas no VIGITEL foi realizado em agosto de 2007).

\section{Agradecimentos}

Agradecemos, inicialmente, às equipes de técnicos das Secretarias de Vigilância em Saúde e de Gestão Estratégica e Participativa do Ministério de Saúde envolvidas na implantação e operacionalização do VIGITEL. Agradecemos, também, às empresas telefônicas Brasil Telecom, Telefônica - Telecomunicações de São Paulo e Telemar Norte Leste, pela imprescindível colaboração prestada ao sistema no sorteio e extração das amostras probabilísticas das linhas telefônicas de cada cidade. Agradecemos, ainda, à Expertise Inteligência e Pesquisa de Mercado Ltda., empresa reponsável pela operacionalização do sistema em 2006, em especial aos seus diretores, supervisores, operadores e equipe técnica. Agradecemos, finalmente, à Coordenação Geral da Política de Alimentação e Nutrição - CGPAN da Secretaria de Atenção à Saúde do Ministério da Saúde, à Secretaria de Saúde do Município de São Paulo e ao Conselho Nacional de Desenvolvimento Científico e Tecnológico - CNPq pelo inestimável apoio prestado ao Núcleo de Pesquisas Epidemiológicas em Nutrição e Saúde da Universidade de São Paulo nos testes de implantação do sistema realizados entre 2003 e 2005 em São Paulo, Botucatu, Belém, Salvador, Florianópolis e Goiânia, bem como a todas as equipes de pesquisadores e às instituições acadêmicas que participaram desses testes.

\section{Referências}

1. World Health Organization. World Health Report 2002. Reducing risks, promoting healthy life. Geneva: WHO; 2002.

2. Ministério da Saúde. Secretaria de Vigilância em Saúde. Departamento de Análise de Situação em Saúde. Saúde Brasil 2006: uma análise da situação de saúde no Brasil. Brasília: Ministério da Saúde; 2006.

3. Malta DC, Cezário AC, Moura L, Morais Neto OL, Silva Jr JB. Construção da vigilância e prevenção das doenças crônicas não trasmissíveis no contexto do sistema único de saúde. Epidemiol Serv Saúde 2006; 15 (3): 47-64.
4. Monteiro CA, Moura EC, Jaime PC, Lucca A, Florindo AA, Figueiredo ICR, Bernal R, Silva NN. Monitoramento de fatores de risco para as doenças crônicas por entrevistas telefônicas. Rev Saúde Pública 2005; 39: 47-57.

5. World Health Organization. Sample size determination in health studies. A practical manual. Geneva: WHO; 1991.

6. Remington PL, Smith MY, Williamson DF, Anda RF, Gentry EM, Hogelin GC. Design, characteristics, and usefulness of state-based behavioral risk factor surveillance: 1981-87. Public Health Rep 1988; 103: 366-75. 
7. World Health Organization. Summary: surveillance of risk factors for noncommunicable diseases. The WHO STEP wise approach. Geneva: WHO; 2001.

8. Ainsworth BE, Haskell WL, Whitt MC, Irwin ML, Swartz AM, Strath SJ, o'Brien WL, Bassett Jr DR, Schmitz KH, Emplaincourt PO, Jacobs Jr DR, Leon AS. Compendium of physical activities: an update of activity codes and MET intensities. Med Sci Sports Exerc 2000; 32: S498-504.

9. Stata Corporation. Stata Statistical Sfotware: Release 9.0. Stata Corporation: College Station, TX; 2005.

10. [CDC] Centers for Disease Control and Prevention. Behavioral Risk Factor Surveillance System - BRFSS. Abouth the BRFSS. [on line] 2007. Disponível em http:// www.cdc.gov/brfss/abourth.htm [Acessado em 20 de junho de 2007].

11. Ministério da Saúde e Instituto Nacional de Câncer. Inquérito domiciliar sobre comportamentos de risco e morbidade referida de doenças e agravos não transmissíveis: Brasil, 15 capitais e Distrito Federal, 20022003. Rio de Janeiro: INCA; 2004.

12. Ministério da Saúde. VIGITEL Brasil 2006. Vigilância de fatores de risco e proteção para doenças crônicas por inquérito telefônico: estimativas sobre freqüência $e$ distribuição sócio-demográfica de fatores de risco e proteção para doenças crônicas nas capitais dos 26 estados brasileiros e no Distrito Federal em 2006. Brasília: Ministério da Saúde; 2007.
13. $[\mathrm{CDC}]$ Centers for Disease Control and Prevention. Technical Information and Data. Technical Documents and Survey Data. Behavioral Risk Factor Surveillance System - BRFSS Weightin Formula. [on line] 2007. Disponível em http://www.cdc.gov/brfss/ technical_infodata/weighting.htm [Acessado em $20 \mathrm{de}$ junho de 2007].

14. Remington PL, Smith MY, Williamson DF, Anda RF, Gentry EM, Hogelin GC. Design, characteristics, and usefulness of state-based behavioral risk factor surveillance: 1981-87. Public Report Reports 1988; 103 (4): 366-75.

15. Kempf AM, Remington PL. New challenges for telephone survey research in the twenty-first century. Annu Rev Public Health 2007; 28: 113-26.

16. Silva NN. Amostragem probabilistica. 2a ed. revis. São Paulo: EDUSP; 2001.

17. Kish L. Survey sampling. NY: John Wiley \& Sons; 1965.

18. Waksberg J. Sampling methods for random digit dialing. $J$ Am Stat Assoc 1978; 73(361): 40-06. 